\title{
Cancer on Testicle Not Descended: Clinical and Therapeutic Aspects of 7 Cases
}

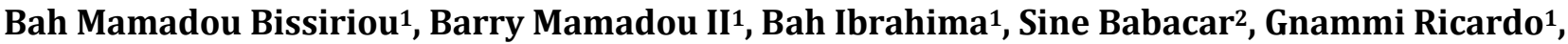 \\ Cissé Demba', Sow Yaya ${ }^{2}$, Diao Babacar ${ }^{2}$
}

${ }^{1}$ Department of Urology, Andrology of the Ignace Deen National Hospital CHU of Conakry, Conakry, Guinea

${ }^{2}$ Department of Urology, Andrology of Aristide Le Dantec Hospital, Dakar, Senegal

Email: drbahmamadou@yahoo.fr

How to cite this paper: Bissiriou, B.M., Mamadou II, B., Ibrahima, B., Babacar, S., Ricardo, G., Demba, C., Yaya, S. and Babacar, D. (2020) Cancer on Testicle Not Descended: Clinical and Therapeutic Aspects of 7 Cases. Open Journal of Urology, 10, 158-166.

https://doi.org/10.4236/oju.2020.105018

Received: March 6, 2020

Accepted: May 6, 2020

Published: May 9, 2020

Copyright $\odot 2020$ by author(s) and Scientific Research Publishing Inc. This work is licensed under the Creative Commons Attribution International License (CC BY 4.0).

http://creativecommons.org/licenses/by/4.0/

\begin{abstract}
Objective: To study the clinics and therapeutics of testicular cancer not descended in Senegal. Patients and Methods: This is a retrospective study over a period of 15 years between January 1997 and January 2012. It focused on 07 patients. Results: The average hospital incidence was less than one case per year. The average age of patients was 30.7 years with a median of 28 (range, 21 years and 38 years). The reasons for consultation were dominated by the existence of an abdominal or pelvic mass associated with an emptiness of the stock market. Orchiectomy was the main therapeutic gesture. It was performed by transperitoneal route. CT-TAP was performed in all cases and revealed a tumor independent of the liver of the spleen or kidneys, developed on an undescended testicle. Four cases of lumbar-aortic lymph node metastasis were noted. Histologically, we noted four cases of embryonic carcinoma and three cases of seminoma. Four patients died within six months postoperatively. Two in an intestinal obstruction chart, one in a peritoneal carcinomatosis chart and one patient in a pulmonary embolism chart. Two had a 4-year survival without recurrence. One patient had a 7-year survival without recurrence. At the time of the counting, these three patients were lost sight off. Conclusion: Intra-abdominal or pelvic development of testicular cancer is rare. It constitutes a major subsequent risk of the undescended testicle.
\end{abstract}

\section{Keywords}

Cancer, Undescended Testicle, Embryonic Carcinoma, Seminoma

\section{Introduction}

Cancers of the testis are rare; they represent the first tumor in humans between 20 and 35 years. Their incidence is increasing, it is higher in the industrialized 
countries, very low in Africa and Asia [1].

Worldwide, the incidence varies between 0.2 and 9.2 cases/100,000/year. The incidence has been increasing sharply over the past 25 years [2]. It is clearly above $0.1 \%$ in subjects with cryptorchid testicles. Up to $95 \%$ of testicular tumors originate in germ cells, the rest being mainly represented by lymphomas and certain tumors of the gonadal stroma [3].

The undescended testicle is correlated with a significant rate of degeneration. Intra-abdominal or pelvic development of testicular cancer is rare. It constitutes a major subsequent risk of the undescended testicle. The diagnosis and early lowering of undescended testes in the bursa remain the only way to fight this form of testicular cancer. These forms of testicular cancer are diagnosed at very advanced stages, making most of them inaccessible to any curative therapy [4].

Generally, in developing countries, cancers are a public health problem because of the absence of a national care policy.

The purpose of our work was to study the clinical and therapeutic aspects of undescended testicular cancer in Senegal.

\section{Patient and Methods}

This is a retrospective study over a period of 15 years between January 1, 1997 and December 31, 2012. We targeted all cases of testicular cancer diagnosed and managed in the department during the study period and from which we have extracted those from undescended testicular cancer.

We had included in our study, patients who were hospitalized for intra-abdominal or intra-pelvic testicular cancer, confirmed on pathological examination of the operating room.

Exclusion criteria were all patients who were hospitalized for an intra-abdominal or intra-pelvic testicular tumor without histological confirmation or for an intra-scrotal tumor.

The parameters studied were: age at the time of diagnosis, circumstances of discovery, physical examination data, results of complementary examinations (tumor markers, abdominal-pelvic ultrasound and thoraco-abdominopelvic computed tomography), treatment and the future of patients (healing, death, recurrence, progression).

The limits of this study relate to the difficulty of follow-up due to the fact that most of our patients came from the interior of the country, hence their inaccessibility for regular follow-up.

To this must be added the absence of additional treatment (chemotherapy, radiotherapy) which would have made it possible to better assess the outcome of the treatment.

\section{Results}

We collected 07 files of patients supported for undescended testicular cancer.

The average age of the patients was 30.7 years with a median of 28 years 
Table 1. Distribution of patients by reason of consultation.

\begin{tabular}{cc}
\hline Reasons for consultation & Number of cases \\
\hline Abdominal mass & 5 \\
Pelvic mass & 2 \\
Abdominal pain & 3 \\
Alteration of the general condition & 4 \\
\hline
\end{tabular}

(range 21 to 38 years).

Hospital incidence was less than one case every two years.

The reasons for consultation were dominated by the existence of an abdominal or pelvic mass (Table 1 ) associated with an empty purse.

A case of invasion of the peritoneum with presence of nodules perceptible subcutaneous was noted.

Tumor markers were assayed in five patients. The human gonadotropic hormone level assay performed in 4 patients was elevated in all cases. Alpha fetoprotein was elevated in 1 out of 4 patients. LDH was dosed in 1 case and was elevated 1.5 times normal.

An assay of carcinoembryonic antigen was performed in three patients. The rate was normal in all cases.

CT-TAP was performed in all cases and revealed a tumor independent of the liver, spleen or kidneys, developed on an undescended testicle (Figure 1 and Figure 2). Four cases of lumbar-aortic lymph node metastasis were noted.

Orchiectomy was the main therapeutic gesture. It was performed by transperitoneal route.

Histologically, we noted four cases of embryonic carcinoma and three cases of seminoma. No additional treatment (chemotherapy or radiotherapy) or ganglion dissection was performed.

The average patient follow-up was 27.7 months (range: 1 month and 84 months).

Four patients died within six months postoperatively. Two in an intestinal obstruction chart (Patients 1 and 3 ), one in a peritoneal carcinomatosis chart (Patient 2) and one patient in a pulmonary embolism chart (Patient 6).

Two patients had a 4-year survival without recurrence (Patients 4 and 5). One patient had a 7 -year survival without recurrence (Patient 7). Table 2 summarizes the age, clinical stage, treatment and survival of patients.

\section{Discussion}

The undescended testicle is the most important risk factor for testicular cancer. Its intra-abdominal location is rare and poses a diagnostic problem. The absence of symptoms in case of undescended testis is responsible for its trivialization, while the consequences will be felt 15 to 20 years later.

In our study hospital incidence was less than one case every 2 years. This in 


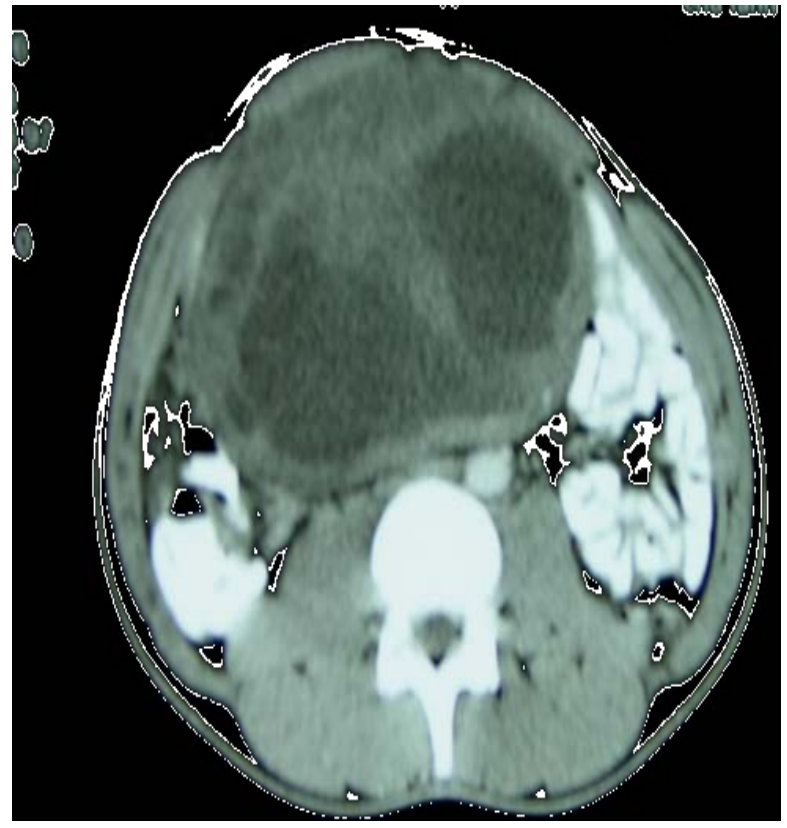

Figure 1. Testicular tumor of testicular origin with areas of necrosis.

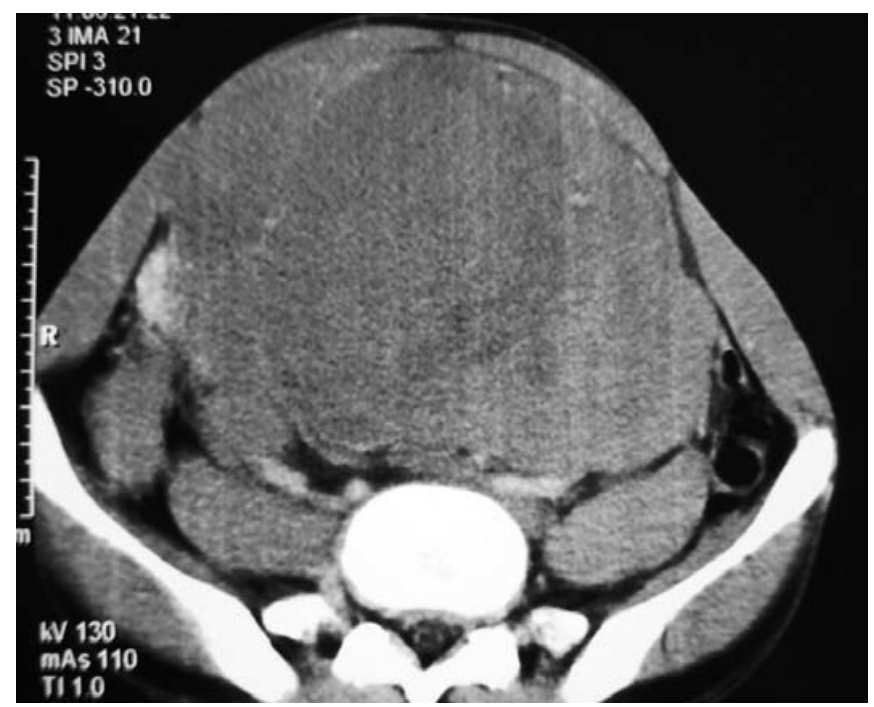

Figure 2. Pelvic tumor of testicular origin.

Table 2. Summary of data.

\begin{tabular}{ccccccc}
\hline Patients & Age & Location & Histology & Stages & Complementary treatment & Patient monitoring \\
\hline 1 & 23 & Pelvic & Embryonic carcinoma & N2M1bS1 & No & Deceased 5 months after surgery \\
2 & 38 & Abdominal & Embryonic carcinoma & N2M1bS1 & No & Décédé un mois après chirurgie \\
3 & 30 & Abdominal & Embryonic carcinoma & N2M1bS1 & No & Deceased 6 months after surgery \\
4 & 32 & Pelvic & Embryonic carcinoma & N0M0SX & No & Was alive 4 years after surgery \\
5 & 34 & Abdominal & Anaplastic seminoma & N0M0Sx & No & Was alive 4 years after surgery \\
6 & 37 & Abdominal & Pure seminoma & N3M1aS1 & No & Deceased 2 months after surgery \\
7 & 21 & Abdominal & Pure seminoma & N0M0Sx & No & Was alive 7 years after surgery \\
\hline
\end{tabular}


cidence is lower than that of the overall incidence of testicular cancer in West Africa. Ouattara et al. [4] in Cotonou, reported three cases of testicular cancer in three years with a frequency of $1.9 \%$ of all urologic cancers. In Burkina Faso, Goumbri et al. [5], over a 20-year study period, found 10 cases of testicular cancer and estimated the incidence at $0.25 \%$ of all cancers.

An increase in the incidence of testicular cancer has been observed in most countries of the world over the last 50 years with a greater increase in Europe [6] [7].

Testicular cancer is the most common cancer in men between the ages of 15 and 35 [8]. It is the second leading cause of cancer death in people under 50 years of age after leukemia [9].

Our results confirm the predominance of testicular tumors in young adults and their rarity at extreme ages. These results are consistent with those of the Sow et al. [10] from Goïta [11] and Niang [12] where the most affected age group was 30 - 40 years old.

The vacuity of the bursa associated with an abdominal or pelvic mass and the deterioration of the general state made it possible to suspect the diagnosis in the seven patients. The right testicle was the most affected in our series (Five times out of seven). The predominance is on the left for Valla et al. [13] as well as for Goïta [11].

For Niang [12] as well as in our series, the digestive symptomatology was in the foreground and misplaced the diagnosis. It is in this context that some of our patients stayed in internal medicine before being transferred to urology.

The undescended testicle is the major recognized risk factor for testicular cancer [8]. Any man who has had an undescended testicle at birth is four times more likely to develop a testicular tumor [14] [15].

The intra-abdominal location of the testis is correlated with a significant rate of degeneration and is a diagnostic problem. Hence the need for systematic palpation of the scrotum in front of any intra-abdominal mass in men.

In our series, tumor markers were measured in five (5) of our patients before the start of treatment. These markers were human gonadotropic hormone, $\alpha$ fetoprotein, L.D.H (lactate dehydrogenase) and A.C.E (Carcino-Embryonic Antigen).

The human gonadotropic hormone assay was high in four (4) of our patients, in whom the histology concluded embryonic carcinoma (3 cases) and seminoma (1 case). In seminomatous tumors, the increase in this rate was moderate $(<100$ IU). Human gonadotropic hormone is secreted mainly by embryonic choriocarcinomas and carcinomas and by $10 \%$ to $15 \%$ of seminomas [16].

Alpha fetoprotein was elevated in one patient with embryonic carcinoma and was normal in three others. According to the literature an elevation of alpha fetoprotein reflects the presence of a non-seminomatous germ cell tumor. A high level of a fetoprotein with seminoma diagnosis should encourage an anatomic-pathological study of the histological slide, in the absence of associated hepatic pathology [17]. 
L.D.H: It was dosed in one patient and was elevated (patient 6). It is increased in $50 \%$ of patients with seminoma at the time of diagnosis. It is not specific and is insensitive; but as for the other two tumor markers, it has a prognostic significance [16].

ACE: It was dosed in three (3) patients and was in the standards. The intra-abdominal development of tumors has been the origin of this marker which has no interest in the diagnosis and management of testicular tumors.

The abdominal and pelvic ultrasound was not able to specify in 4 cases out of 7, the organ at the expense of which the tumor has developed.

All patients had CT. She was more sensitive than ultrasound in the detection of intra-abdominal testicular tumors. It is the reference examination because it makes it possible to ask the diagnosis and to appreciate the tumor extension.

Abdominopelvic CT is routinely recommended in the initial assessment and follow-up of germ cell tumors [2].

Thoracic CT is the most sensitive examination for detecting lung metastases or mediastinal lymphadenopathy. It is systematically recommended in case of non-seminomatous germinal tumours (NGT) and is part of the initial balance sheet. In $10 \%$ of the NGT, small subpleural nodules are present and are invisible on a standard radiograph [2].

Embryonic carcinomas were more common. However, several studies have shown the predominance of seminomatous tumors in cases of undescended testicular cancer [18] [19].

Coupland [18] concluded that the risk of association between seminoma and undescended testis was greater than that of other tumors (odds ratio 5.3 vs. 3.0) and this association would be larger (odds ratio 11.9 vs. 5,1 ) when the patient's age was greater than or equal to 32 years.

The main treatment in our study was surgery (orchiectomy). It was performed by laparotomy with tumor resection. No lymph node dissection or complementary treatment was administered in our series. It is the same in the 8 patients of Goïta [11] in Mali where orchiectomy was the only treatment.

The treatment of testicular cancers depends on the histological nature and stage of the tumor. In our study, we counted 4 patients who had a non-seminomatous tumor and 3 patients had a seminomatous tumor at different stages.

The patients $(1 ; 2 ; 3 ; 4)$ had embryonic carcinoma on undescended testicle. They were ranked N2M1bS1 for the first three. A chemotherapy with 4 cycles every 21 days according to the recommendations of the AFU could have been carried out [17].

In our countries, the scarcity or even the exorbitant costs of chemotherapy products is a difficulty in the effective management of patients who have testicular cancer.

Three patients $(5 ; 6 ; 7)$ had a seminomatous tumor classified N0M0SX, N0M0SX, N3M1aSX, could have had a para-aortic prophylactic radiotherapy at the dose of 20 to 24 Gy which remains the recommended standard [20] or chemotherapy (3 cures of BEP or 4 cures of EP according to the recommendations of the AFU) for 
the patient who had the metastasized tumor.

The practice of radiotherapy in Senegal is based on obsolete means using cobalt. We noted the absence of conformal radiation therapy with intensity modulation which has the advantage of being more effective with fewer side effects. Sperm preservation has not been performed in our patients. To try to preserve the reproductive potential of cancer patients [21]; this preservation before a chemo or radiotherapeutic treatment has been proposed for more than 20 years. It is suggested systematically before orchiectomy for at least one sample.

In our study, no action was taken on the possibility of future procreation of patients. This would be related to the lack of structure for the management of these patients in the field of reproductive health.

In our series, the average follow-up was 27.7 months. As for the Goïta study [11] from the third month after the surgical treatment, none of the patients was seen again.

The specific mortality of testicular cancer in our study was high. This rate is comparable to that of Ouattara et al. [4] in Benin, who reported a mortality rate of $33.3 \%$. This rate remains very high compared to that reported by Western series such as those of Miladi et al. [22] involving 60 patients with low testicular germ cell death rates ( $0 \%$ for HCWs and $4 \%$ for NERs at 7 years).

\section{Conclusion}

The undescended testicle is the most important risk factor for testicular cancer. Its intra-abdominal location is rare and poses a diagnostic problem. The absence of symptoms in the case of an undescended testicle is responsible for its trivialization, while the consequences will be felt 15 to 20 years later. In our countries, the scarcity or even exorbitant cost of chemotherapy products constitutes a difficulty in the effective management of patients with testicular cancer.

\section{Conflicts of Interest}

The authors declare no conflicts of interest regarding the publication of this paper.

\section{References}

[1] Bray, F., Richiardi, L., Ekbom, A., et al. (2006) Trends in Testicular Cancer Incidence and Mortality in 22 European Countries: Continuing Increases in Incidence and Decline in Mortalities. International Journal of Cancer, 118, 3099-3111. https://doi.org/10.1002/ijc. 21747

[2] Durand, X., Rigaud, J., Avances, C., et al. (2010) Recommandations en Onco-Urologie 2010: Tumeurs germinales du testicule. Progrès en Urologie, 4, S297-S311. https://doi.org/10.1016/S1166-7087(10)70046-4

[3] Elder, J.S. (1987) Cryptorchidism: Isolated and Associated with Other Genitourinay Defects. Pediatric Clinics of North America, 34, 1033-1035. https://doi.org/10.1016/S0031-3955(16)36301-5

[4] Ouattara, A., et al. (2012) Épidémiologie des cancers urologiques au Centre national 
hospitalier universitaire Hubert Koutoukou Maga Cotonou, Bénin. Analyse d'une série hospitalière de 158 cas. Progrès en Urologie, 5, 261-265.

https://doi.org/10.1016/j.purol.2011.12.003

[5] Mlompo, G.O., Domagni, O.E., Sanou, A.M., Konsegre, V. and Soudre, R.B. (2009) Aspects épidémiologiques et histopathologiques des cancers au Burkina Faso. Journal Africain du Cancer, 1, 207-211. https://doi.org/10.1007/s12558-009-0052-x

[6] Huyghe, E., Plante, P. and Thonneau, P.F. (2007) Testicular Cancer Variations in Time and Space in Europe. European Urology, 51, 621-628. https://doi.org/10.1016/j.eururo.2006.08.024

[7] Purdue, M.P., Devesa, S.S., Sigurdson, A.J. and McGlynn, K.A. (2005) International Patterns and Trends in Testis Cancer Incidence. International Journal of Cancer, 115, 822-827. https://doi.org/10.1002/ijc.20931

[8] Jouannet, P. (2012) Le cancer du testicule: Facteurs de risque génétiques et environnementaux. Andrologie, 22, 10-19. https://doi.org/10.1007/s12610-012-0164-5

[9] Tamgac, F., Tofighi, M., Baillet, G., Weinmann, P. and Moretti, J.-L. (2004) The Interest of ${ }^{18}$ FDG-PET in the Management of Testicular Cancer. La Presse Médicale, 33, 270-276. https://doi.org/10.1016/S0755-4982(04)98554-5

[10] Sow, M., Nkegoum, B. and Essame Oyono, J.L. (2006) Aspects épidémiologiques et histopathologiques des tumeurs urogénitales au Cameroun. Progrès en Urologie, 16, 36-39.

[11] Goïta, A. (2007) Aspects épidémio-cliniques et prise en charge des tumeurs testiculaires dans le service d'urologie du C.H.U du Point-G. Th Med Bamako 2006-2007.

[12] Niang, L., Diao, B., Gueye, S.M., Fall, P.A., Moby-Mpah, H., Jalloh, M., Ndoye, A. and Diagne, B. (2007) Cancer sur testicule non descendu intra-abdominal à propos de 5 cas. Progrès en Urologie, 17, 947-949.

https://doi.org/10.1016/S1166-7087(07)92394-5

[13] Valla, J.S., et al. (1999) Tumeurs bénignes du testis chez l'enfant. Annal Urologie, 33, 333-341.

[14] Cook, M.B., Akre, A., Forman, D., et al. (2010) A Systematic Review and Meta-Analysis of Perinatal Variables in Relation to the Risk of Testicular Cancer-Experiences of the Son. International Journal of Epidemiology, 39, 1605-1618.

https://doi.org/10.1093/ije/dyq120

[15] Schnak, T.H., Poulsen, G., Myrup, G., et al. (2010) Familial Coaggregation of Cryptorchidism, Hypospadias and Testicular Germ-Cell Cancer: A Nationwide Cohort Study. Journal of the National Cancer Institute, 102, 187-192. https://doi.org/10.1093/jnci/djp457

[16] Haillot, O. (1992) Quoi de neuf dans le diagnostic des tumeurs du testicule? Progrès en Urologie, 2, 488-497.

[17] Javadpour, N. (1985) Tumor Markers in Testicular Cancer. An Update. Progress in Clinical and Biological Research, 203, 141-154.

[18] Coupland, C.A., Chilvers, C.E., Davey, G., Pike, M.C., Oliver, R.T. and Forman, D. (1999) Risk Factors for Testicular Germ Cell Tumours by Histological Tumour Type. United Kingdom Testicular Cancer Study Group. British Journal of Cancer, 80, 1859-1863. https://doi.org/10.1038/sj.bjc.6690611

[19] Helali, K., Amouri, A. and Haddad, B. (2005) Dégénérescence d'un testicule ectopique intra abdominal: A propos de deux cas. Tunisie Chirurgicale A, 3, 151-154.

[20] Houlgatte, A. and Bauduceau, O. (2005) Tumeurs germinales séminomateuses du testicule: Diagnostic et traitement. Annales d Urologie, 39, 159-169. 
https://doi.org/10.1016/j.anuro.2005.09.004

[21] Mottet, N. (2000) Cancer du testicule et fertilité masculine. Progrès en Urologie, 10, 193-199.

[22] Miladi, M., Peyromaure, M., Remi, J., Beuzeboc, P., Debre, B. and Zerbib, M. (2003) Tumeurs germinales du testicule: Etude pronostique. Progrès en Urologie, 13, 92-97. 